Check for updates

Cite this: RSC Adv., 2018, 8, 5189

\title{
Electrochemical characteristics of amorphous silicon carbide film as a lithium-ion battery anode $\uparrow$
}

\author{
X. D. Huang, (D) ${ }^{\star a}$ F. Zhang, ${ }^{a}$ X. F. Gan, ${ }^{a}$ Q. A. Huang, ${ }^{a}$ J. Z. Yang, ${ }^{* b}$ P. T. Lai ${ }^{c}$ \\ and W. M. Tang ${ }^{\star d}$
}

The electrochemical reactions of $\mathrm{SiC}$ film with $\mathrm{Li}^{+}$have been investigated by electrochemical characterization and X-ray photoelectron spectroscopy. The SiC film is prepared by inductively-coupledplasma chemical-vapor-deposition (ICP-CVD) technique and displays an amorphous state due to the low processing temperature $\left(\sim 350^{\circ} \mathrm{C}\right)$. An irreversible reaction of $\mathrm{SiC}$ with $\mathrm{Li}^{+}$occurs with the formation of lithium silicon carbide $\left(\mathrm{Li}_{x} \mathrm{Si}_{y} \mathrm{C}\right)$ and elemental $\mathrm{Si}$, followed by a reversible alloying/dealloying reaction of the elemental $\mathrm{Si}$ with $\mathrm{Li}^{+}$. The $500 \mathrm{~nm} \mathrm{SiC}$ film shows an initial reversible specific capacity of $917 \mathrm{~mA} \mathrm{~h} \mathrm{~g}^{-1}$ with a capacity retention of $41.0 \%$ after 100 cycles at $0.3 \mathrm{C}$ charge/discharge current, and displays much better capacity retention than the $\mathrm{Si}$ film $(5.2 \%)$. It is found that decreasing the $\mathrm{SiC}$ thickness effectively improves the specific capacity by enhancing the reaction kinetics but also degrades the capacity retention (for $250 \mathrm{~nm} \mathrm{SiC}$, its initial capacity is $1427 \mathrm{~mA} \mathrm{~h} \mathrm{~g}{ }^{-1}$ with a capacity retention of $25.7 \%$ after 100 cycles). The better capacity retention of the $500 \mathrm{~nm} \mathrm{SiC}$ anode is mainly because residual $\mathrm{SiC}$ exists in the film due to its incomplete reaction caused by its lower reaction kinetics, and it has high hardness and can act as a buffer matrix to alleviate the anode volume change, thus improving the mechanical stability and capacity retention of the SiC anode.

Received 15th November 2017

Accepted 26th January 2018

DOI: 10.1039/c7ra12463e

rsc.li/rsc-advances during electrochemical charge (delithiation) and discharge (lithiation) cycling. ${ }^{6-13}$ As alternatives, silicon oxide and silicon nitride films can achieve considerable capacity as well as good capacity retention, ${ }^{\mathbf{1 4 - 2 3}}$ thus having receiving much attention. Moreover, it has been demonstrated that $\mathrm{C}$ introduced to $\mathrm{Si}$ (in the form of $\mathrm{Si}-\mathrm{C}$ composite or as an encapsulation layer on the Si surface) is effective to accommodate the volume change and thus improve the LIB capacity retention. ${ }^{24-28}$ However, the formation of silicon carbide ( $\mathrm{SiC}$ ) easily happens when $\mathrm{C}$ is in contact with Si due to the strong bonding tendency between them..$^{24,25}$ Unlike silicon oxide and silicon nitride, ${ }^{16-23}$ since SiC has been regarded as an inactive anode material for LIB, many efforts have been made to prohibit the formation of SiC during introducing $\mathrm{C}$ to $\mathrm{Si}$, which inevitably complicate the fabrication process and cost. ${ }^{24-30}$ Until recently, both theoretical and experimental results have demonstrated that $\mathrm{SiC}$ can act as a LIB anode and achieve a high reversible capacity (e.g., $1200 \mathrm{~mA} \mathrm{~h} \mathrm{~g}^{-1}$ over 200 cycles at a C/30 current rate in ref. 33). ${ }^{31-35}$ Consequently, SiC has received an increasing interest in recent years. However, little work has been paid to the electrochemical reaction mechanisms of the SiC anode with $\mathrm{Li}^{+}{ }^{32,33}$ Zhang et al. reported that the reaction mechanisms of the $\mathrm{SiC}$ film with $\mathrm{Li}^{+}$follow the conversion reaction; that is, conversion reaction from SiC to elemental Si occurs reversibly, followed by a reversible alloying/dealloying reaction of $\mathrm{Si}$ with $\mathrm{Li}^{+} \cdot{ }^{32}$ According to the above reaction mechanisms, the capacity of the $\mathrm{SiC}$ anode is calculated to be $5626 \mathrm{~mA} \mathrm{~h} \mathrm{~g}^{-1}$, which is

\footnotetext{
${ }^{a}$ Key Laboratory of MEMS of the Ministry of Education, Southeast University, Nanjing 210096, China.E-mail: xdhuang@seu.edu.cn

${ }^{b}$ School of Chemistry and Chemical Engineering, Nanjing University of Science and Technology, Nanjing 210094, China. E-mail: jiazhiyang@sina.com

${ }^{c}$ Department of Electrical and Electronic Engineering, The University of Hong Kong, Hong Kong, China

${ }^{d}$ Department of Applied Physics, The Hong Kong Polytechnic University, Hong Kong, China.E-mail:wm.tang@polyu.edu.hk

$\dagger$ Electronic supplementary information (ESI) available. See DOI: 10.1039/c7ra12463e
} 
much higher than its experimental value $\left(309 \mathrm{~mA} \mathrm{~h} \mathrm{~g} \mathrm{~g}^{-1}\right){ }^{32}$ Therefore, the mechanisms are still unclear and need to be carefully investigated. So far, SiC used in the LIB is usually in the form of nanostructure (e.g., nanoparticle and nanowire) $;^{33-35}$ for comparison, the primary form of SiC in the microelectronics is film. Compared with the nanostructured SiC, advantages of the SiC film include better uniformity, higher deposition rate, more compatibility with the microelectronic process and thus easier integration with electronic and MEMS devices. It is known that the form of the LIB anode has a great influence on its electrochemical characteristics, for instance, the nanostructured anode usually has higher surface area and higher activity than the film counterpart. Therefore, even though the nanostructured SiC has been demonstrated to be a promising anode material, the feasibility of SiC film as the anode still needs to be carefully investigated.

\section{Experimental}

\subsection{Preparation of the anode films}

$500 \mathrm{~nm} \mathrm{SiC} \mathrm{film} \mathrm{was} \mathrm{deposited} \mathrm{on} \mathrm{stainless-steel} \mathrm{substrate} \mathrm{by}$ inductively-coupled-plasma chemical-vapor-deposition (ICPCVD, Oxford 380) technique at $350{ }^{\circ} \mathrm{C}$, which is the common technique for $\mathrm{SiC}$ deposition in the microelectronics. ${ }^{36}$ During the deposition, $\mathrm{Ar}, \mathrm{SiH}_{4}$ and $\mathrm{CH}_{4}$ were used as precursors and their flow rates were $30 \mathrm{sccm}, 30 \mathrm{sccm}$ and $45 \mathrm{sccm}$ respectively, and the deposition rate of the film is about $18 \mathrm{~nm} \mathrm{~min}^{-1}$. For practical applications, a relatively thick SiC film is desirable for improving the anode capacity; however, in order to investigate the effects of the film thickness on the electrochemical performance of the SiC anode, a thin (ca. $250 \mathrm{~nm}$ ) SiC film was also prepared. For comparison, $500 \mathrm{~nm}$ Si film was also prepared on stainless-steel substrate by sputtering using a pure Si target at room temperature, followed by a thermal annealing at $350{ }^{\circ} \mathrm{C}$ in an $\mathrm{Ar}$ ambient. The thermal annealing was adopted to ensure that the Si film possessed similar thermal budget as the SiC one.

\subsection{Characterization}

The thickness of the films was measured by using ellipsometry (Horiba Uvisel). For electrochemical characterization, the SiC and Si electrodes were assembled into CR2016-type coin cells with Celgard 2400 as separator, $1 \mathrm{M} \mathrm{LiPF}_{6}$ dissolved in ethylene carbonate/dimethyl carbonate $(\mathrm{v} / \mathrm{v}=1: 1)$ as electrolyte, and $\mathrm{Li}$ foil as counter electrode. Cyclic voltammetry was recorded at a scanning rate of $0.1 \mathrm{mV} \mathrm{s}^{-1}$ between $0 \mathrm{~V}$ and $3 \mathrm{~V}$ versus $\mathrm{Li} / \mathrm{Li}^{+}$ (CHI 660E). Galvano-static cycling was carried out between $0.01 \mathrm{~V}$ and 3.0 $\mathrm{V}$ versus $\mathrm{Li}^{+} / \mathrm{Li}$ (Land CT2001A). To examine the film properties after electrochemical cycling, the anode electrodes were took out from the coin cells after 100 charge/ discharge cycles and dried in an Ar ambient. The crystalline structures of the films were investigated by X-ray diffraction (XRD, Bruker D8 Advance). The morphologies of the films were characterized by scanning electron microscopy (SEM, Zeiss Ultra Plus). The elemental compositions of the films were evaluated by energy dispersive X-ray spectrometry (EDX). The chemical states of the films were measured by X-ray photoelectron spectroscopy (XPS, PHI Quantera II) and the XPS penetration depth is about $10 \mathrm{~nm}$. The XPS spectra were calibrated according to ref. 37. During the XPS measurements, the depth profiling was performed by $\mathrm{Ar}^{+}$sputtering with an etching rate of about $3.5 \mathrm{~nm} \mathrm{~min}^{-1}$.

\section{Results and discussion}

Fig. 1 shows the Si 2p XPS spectrum as well as the curve-fitting lines for the $500 \mathrm{~nm} \mathrm{Si}$ and SiC samples before electrochemical cycling. For the Si sample, its spectrum consists of one intense peak at $99.3 \mathrm{eV}$ and one weak peak at $101.0 \mathrm{eV}$, which can be assigned to elemental $\mathrm{Si}$ and $\mathrm{SiO}_{x}$ respectively. ${ }^{37} \mathrm{SiO}_{x}$ is formed due to the oxidation reaction of elemental Si with oxygen during the film preparation. For comparison, the spectrum for the SiC sample mainly consists of one intense peak at $100.7 \mathrm{eV}$ and one weak peak at $102.0 \mathrm{eV}$, which agree well with $\mathrm{SiC}$ and $\mathrm{Si}-\mathrm{C}-\mathrm{O}$ respectively. ${ }^{38}$ The formation of $\mathrm{Si}-\mathrm{C}-\mathrm{O}$ can be further confirmed by the $\mathrm{C} 1 \mathrm{~s}$ spectrum as shown in Fig. S1. $\dagger$ Note that no elemental Si component is observed in the SiC sample. The elemental compositions of the $\mathrm{Si}$ and SiC films can be determined by EDX (as seen in Fig. S2 $\dagger$ ). It is found that both the $\mathrm{Si}$ and $\mathrm{SiC}$ films consist of $\mathrm{Si}, \mathrm{C}$ and $\mathrm{O}$ elements. For the Si film, the relative atomic content of the $\mathrm{Si}, \mathrm{O}$ and $\mathrm{C}$ elements is $72.9 \%$, $5.6 \%$ and $21.5 \%$ respectively. The $\mathrm{C}$ element in the Si film is

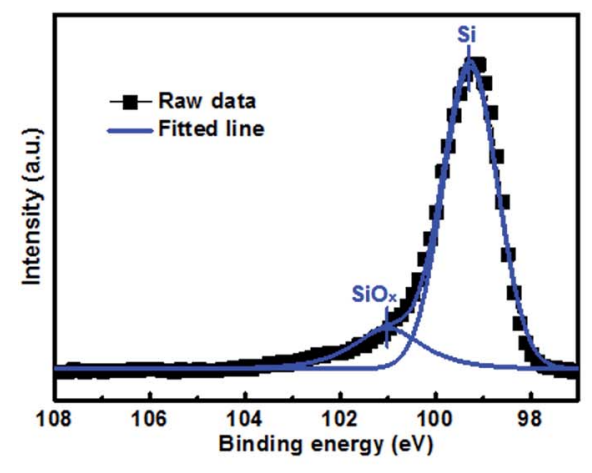

(a)

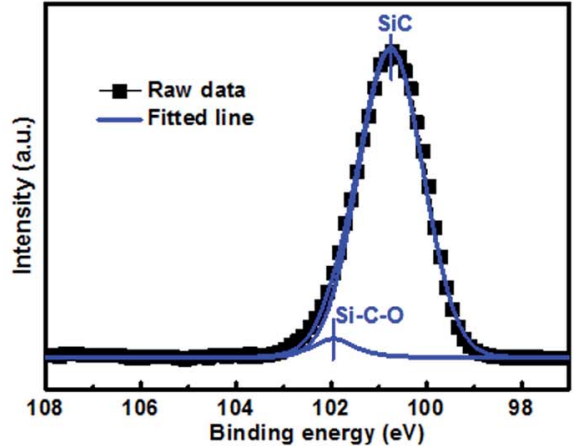

(b)

Fig. 1 Si $2 p$ XPS spectrum for the $500 \mathrm{~nm}$ (a) Si anode film and (b) SiC anode film before electrochemical cycling. The samples are sputtered by $\mathrm{Ar}^{+}$for 1 min before test. 


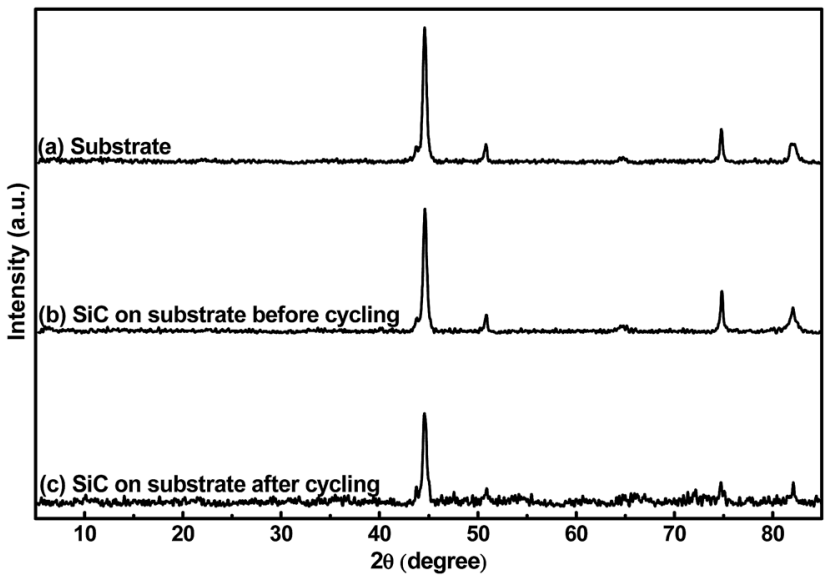

Fig. 2 XRD patterns of (a) the stainless-steel substrate, (b) $500 \mathrm{~nm} \mathrm{SiC}$ on the substrate before cycling and (c) $500 \mathrm{~nm} \mathrm{SiC}$ on the substrate after cycling.

mainly due to the surface contamination and is mainly located at the film surface, and these can be demonstrated by the C $1 \mathrm{~s}$ XPS depth profiling as shown in Fig. S3. $\dagger$ For the SiC film, the atomic content of the $\mathrm{Si}, \mathrm{C}$ and $\mathrm{O}$ elements is $49.8 \%, 45.7 \%$ and $4.5 \%$ respectively, where the atomic ratio between the Si and C elements is close to the ideal stoichiometric ratio. It is worth mentioning that the SiC film has a good thermal stability, which results in its much lower O content $(\sim 5.6 \%)$ than the Si film $(\sim 21.5 \%)$ even though both films go through similar thermal budget. It has been reported that both $\mathrm{SiO}_{x}$ and $\mathrm{Si}-\mathrm{C}-\mathrm{O}$ can act as an active anode and have much better capacity retention than the $\mathrm{Si}$ anode. ${ }^{15-18,38}$ However, in this work, although the $\mathrm{SiO}_{x}$ content ( $\sim 15.6 \%$ from Fig. 1(a)) in the Si film is much higher than the Si-C-O content (4.1\% from Fig. 1(b)) in the SiC film, the SiC sample displays much better capacity retention than the Si sample (as seen in Fig. 6 and the details will be discussed later), suggesting that the $\mathrm{SiC}$ component plays the dominant role in the anode capacity retention as well as the anode reaction.

Fig. 2 shows the crystalline patterns of the stainless-steel substrate and the $500 \mathrm{~nm} \mathrm{SiC} \mathrm{film} \mathrm{on} \mathrm{the} \mathrm{substrate} \mathrm{before}$ and after electrochemical cycling. It is found that the samples display same XRD patterns, suggesting that all the patterns are from the substrate and the SiC film (both before and after cycling) is amorphous. The amorphous state of the SiC film should be mainly ascribed to its low thermal processing temperature. Due to its much higher plasma density of the ICPCVD technique, ICP-CVD can adopt much lower thermal processing temperature for the SiC deposition than other techniques (e.g. microwave-plasma CVD and low-pressure CVD, $\left.\geq 1000{ }^{\circ} \mathrm{C}\right) .{ }^{26}$ It is worth pointing out that this lower processing temperature is quite beneficial to suppress the damages to electronic and MEMS devices when they are fabricated together with the LIB, thus helpful to develop an autonomous microsystem. In addition, regarding the materials used as the LIB electrode, it has been reported that the reactions of the amorphous material with $\mathrm{Li}^{+}$has better reversibility than the

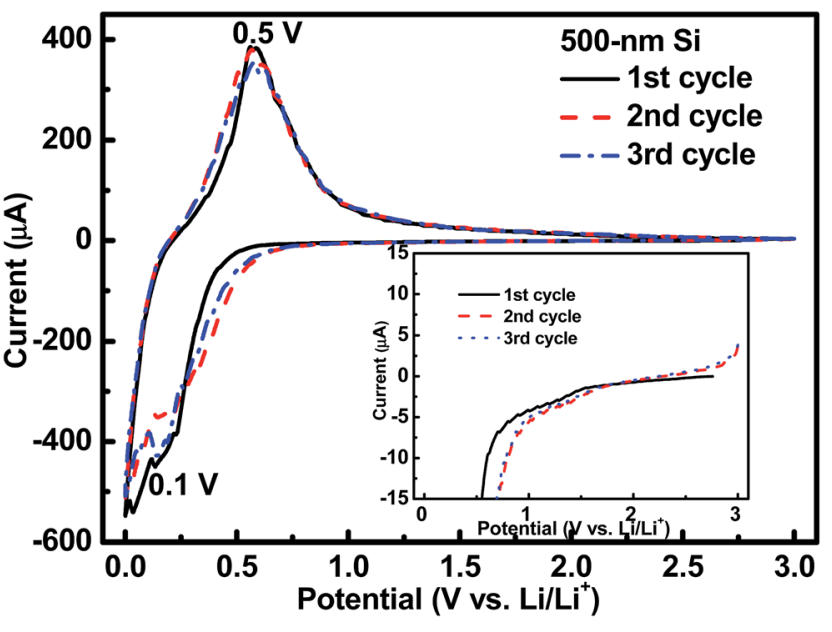

(a)

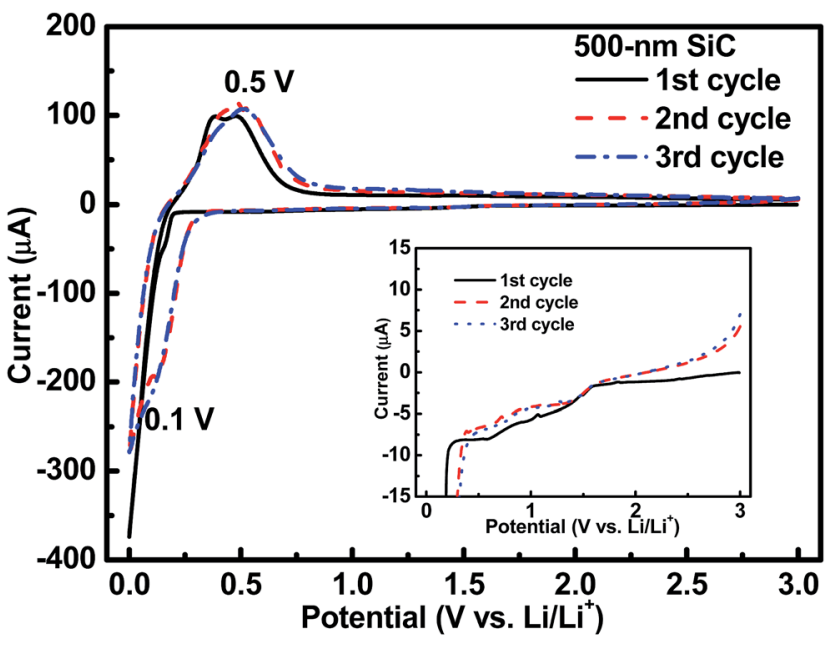

(b)

Fig. 3 CV profiles of the $500 \mathrm{~nm}$ (a) Si sample and (b) SiC sample. The inset shows that there is an extra cathodic peak between $0.5-1.5 \mathrm{~V}$ for the SiC sample compared with the Si one.

reactions of the crystalline counterpart with $\mathrm{Li}^{+}{ }^{39}$ Also, the amorphous material would form percolation pathways to facilitate $\mathrm{Li}^{+}$diffusion; consequently, the amorphous material displays higher reaction kinetics than the crystalline counterpart. ${ }^{40,41}$ Furthermore, due to its homogeneous nature, the amorphous material has higher ability to endure the stress induced by the electrode volume changes during repeated electrochemical cycles than the crystalline one; therefore, the former exhibits better capacity retention than the latter. ${ }^{41,42}$ Based on the above hints, the amorphous SiC anode film is expected to obtain better electrochemical performance than the crystalline counterpart.

Fig. 3 shows the cyclic voltammetry (CV) curves of the $500 \mathrm{~nm}$ $\mathrm{Si}$ and SiC samples. As seen in Fig. 3(a), for the Si sample, an obvious cathodic peak at around $0.1 \mathrm{~V}$ and an obvious anodic 
peak at around $0.5 \mathrm{~V}$ can be clearly observed, which agree well with the reversible alloying/dealloying reaction of $\mathrm{Si}$ with $\mathrm{Li}^{+} .^{7-10}$ As shown in Fig. 3(b), this pair of redox peaks can be also found in the SiC sample. However, for the SiC sample, the cathodic peak at around $0.1 \mathrm{~V}$ is very weak in the $1^{\text {st }} \mathrm{CV}$ cycle mainly due to its negligible $\mathrm{Si}$ content (as seen in Fig. 1(b)) and then becomes much stronger in the following cycles, suggesting that more $\mathrm{Si}$ are formed by $\mathrm{SiC}$ to participate in the alloying/ dealloying reaction. In addition, as seen in the inset of Fig. 3, for the SiC sample, its CV curve in the $1^{\text {st }}$ cycle displays a broad cathodic peak between $0.5 \mathrm{~V}$ and $1.5 \mathrm{~V}$ compared with that for the Si sample, indicating the existence of an extra electrochemical reaction in the SiC sample. This peak becomes unclear with cycling, suggesting that the reaction associated with this peak is irreversible and mainly happens in the initial cycle.

Fig. 4 shows the charge/discharge voltage profiles of the $500 \mathrm{~nm} \mathrm{Si}$ and SiC samples at a current density of $0.01 \mathrm{C}$. As seen

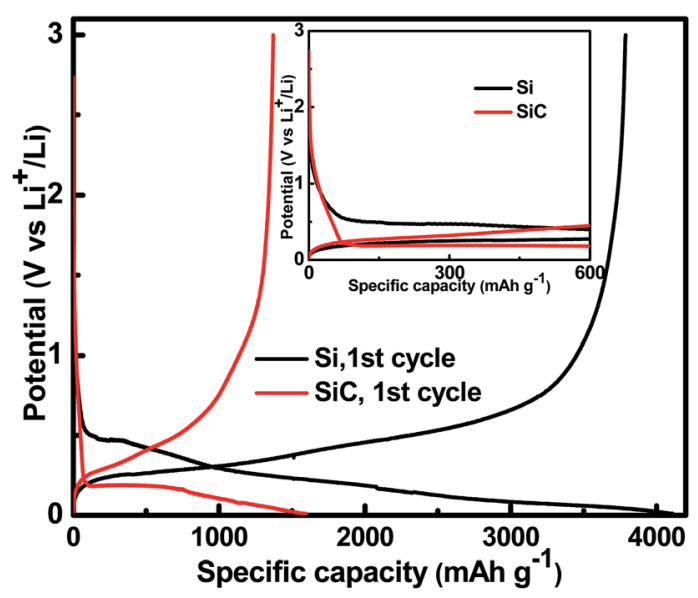

(a)

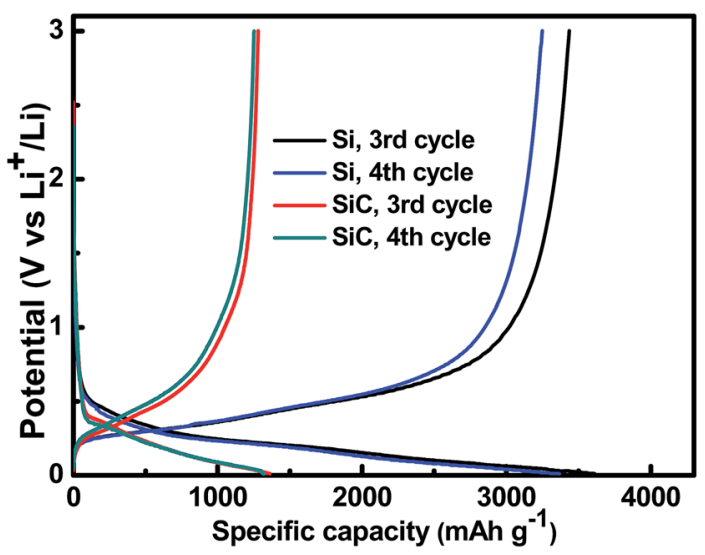

(b)

Fig. 4 Charge/discharge voltage profiles for the $500 \mathrm{~nm} \mathrm{Si}$ and SiC and samples at a current density of $0.01 \mathrm{C}(\mathrm{a})$ in the $1^{\text {st }}$ cycle; (b) in the $3^{\text {rd }}$ and $4^{\text {th }}$ cycles. The inset of Fig. 3(a) shows that the SiC sample displays a slope in the range of $0.5-1.5 \mathrm{~V}$ followed by a voltage overshoot at the initial stage of the $1^{\text {st }}$ discharge process. in the inset of Fig. 4(a), compared with the Si sample, the SiC sample displays a slope in the range of $0.5-1.5 \mathrm{~V}$ followed by a voltage overshoot at the initial stage of the first discharge process. This is a typical characteristic of a reaction with nucleation of a new phase, indicating that significant change occurs in the SiC anode during the first discharge process. ${ }^{21-23}$ Both the slope and overshoot disappear and the SiC sample displays similar voltage profiles to the Si sample in the following cycles (as shown in Fig. 4(b)), suggesting similar electrochemical reactions between them in the following cycles. The Si and SiC samples display an initial charge/discharge capacity of $3787 \mathrm{~mA} \mathrm{~h} \mathrm{~g} \mathrm{~g}^{-1} / 4110 \mathrm{~mA} \mathrm{~h} \mathrm{~g} \mathrm{~g}^{-1}$ and $1371 \mathrm{~mA} \mathrm{~h} \mathrm{~g}^{-1 /}$ $1595 \mathrm{~mA} \mathrm{~h} \mathrm{~g}^{-1}$, corresponding to a coulombic efficiency (CE) of 92.1\% and $86.0 \%$ respectively. The SiC sample displays lower initial capacity and CE than the Si one. This should be due to the extra irreversible reaction happening in the SiC anode as discussed above and the details will be discussed later. It is worth pointing out that both the $\mathrm{CV}$ and charge/discharge voltage profiles of the $\mathrm{SiC}$ anode film in this work are quite different from those of the nanostructured SiC in the literatures, which have reported that the reactions of $\mathrm{SiC}$ with $\mathrm{Li}^{+}$do not involve the formation of $\mathrm{Li}-\mathrm{Si}$ alloy. ${ }^{33-35}$ This suggests different electrochemical reactions between them.

In the ref. 32, the reaction mechanisms of the SiC film with $\mathrm{Li}^{+}$is expressed by

$$
\begin{aligned}
& \mathrm{SiC}+4 \mathrm{Li}^{+}+4 \mathrm{e}^{-} \Leftrightarrow \mathrm{Li}_{4} \mathrm{C}+\mathrm{Si} \\
& \mathrm{Si}+4.4 \mathrm{Li}^{+}+4.4 \mathrm{e}^{-} \Leftrightarrow \mathrm{Si}_{4.4} \mathrm{Li}
\end{aligned}
$$

According to the above equations, conversion reaction from SiC to elemental Si occurs reversibly, followed by a reversible alloying/dealloying reaction of $\mathrm{Si}$ with $\mathrm{Li}^{+}$. The corresponding SiC capacity can be calculated to be $5626 \mathrm{~mA} \mathrm{~h} \mathrm{~g}^{-1}$, which is much higher than the test value $\left(309 \mathrm{~mA} \mathrm{~h} \mathrm{~g}^{-1}\right) .{ }^{32}$ It has been reported that the conversion reaction shown in the eqn (1) can be reversible or irreversible. ${ }^{21,32,42}$ As discussed earlier, there is an irreversible reaction in the initial cycle for the SiC sample, which leads to the formation of elemental Si (and thus higher capacity of the sample) in the following cycles. Therefore, given that the reaction shown in the eqn (1) is irreversible, the corresponding coulombic efficiency of the $\mathrm{SiC}$ anode in the initial cycle is calculated to be $47.6 \%$, which is much lower than the actual value $(86.0 \%)$ in this work. Therefore, according to the above analysis, the conversion reaction is not appropriate to describe the reaction mechanisms of $\mathrm{SiC}$ with $\mathrm{Li}^{+}$in this work; alternatively, we suggest that the reactions of $\mathrm{SiC}$ with $\mathrm{Li}^{+}$ should be followed by

$$
\begin{gathered}
\mathrm{SiC}+x \mathrm{Li}^{+}+x \mathrm{e}^{-} \Rightarrow \mathrm{Li}_{x} \mathrm{Si}_{y} \mathrm{C}+(1-y) \mathrm{Si}(\mathrm{y}<1) \\
\mathrm{Si}+4.4 \mathrm{Li}^{+}+4.4 \mathrm{e}^{-} \Leftrightarrow \mathrm{Si}_{4.4} \mathrm{Li}
\end{gathered}
$$

Due to the strong covalent bonding between $\mathrm{Si}$ and $\mathrm{C}, \mathrm{Li}_{x} \mathrm{Si}_{y} \mathrm{C}$ has higher formation energy than $\mathrm{Li}_{4} \mathrm{C}$, which leads to that change in the Gibbs free energy $(\Delta G)$ caused by the eqn (3) should be more negative than $\Delta G$ caused by the eqn (1). Therefore, the eqn (3) is more likely to occur spontaneously 
than the eqn (1). To gain more insight into the electrochemical reactions, the Si 2p XPS spectrum as a function of $\mathrm{Ar}^{+}$sputtering time $\left(t_{\mathrm{s}}\right)$ is investigated for the $\mathrm{SiC}$ anode at a fully discharge state. As shown in Fig. 5, when $t_{\mathrm{s}}=0 \mathrm{~s}$, no Si spectrum is observed mainly due to the formation of a SEI (solid electrolyte interphase) layer on the sample surface. When $t_{\mathrm{s}}=4 \mathrm{~min}$, a weak Si spectrum begins to appear. The appearance of the Si spectrum at $t_{\mathrm{s}}=4$ min suggests that the SEI thickness is about $10 \mathrm{~nm}$. The SEI layer in this work is thinner than that $(\sim 40 \mathrm{~nm})$ for the nanostructured anode in the literatures, ${ }^{37}$ thus contributing to the higher coulombic efficiency of the anode in this work. ${ }^{32,33,37}$ The spectrum intensity increases with increasing $t_{\mathrm{s}}$ and then tends to be stable as $t_{\mathrm{s}} \geq 10 \mathrm{~min}$. Compared with the $\mathrm{Si}$ 2p spectrum before cycling (as seen in Fig. 1(b), the full width at half maximum (FWHM) is $1.7 \mathrm{eV}$ ), the spectrum (as $t_{\mathrm{s}} \geq 10 \mathrm{~min}$ ) after cycling are significantly broadened (FWHM $\sim 2.8 \mathrm{eV}$ ), suggesting more complex components formed in the anode after cycling. In addition, compared with the spectrum ( $\sim 100.7 \mathrm{eV}$ ) before cycling, the spectrum at the discharge state makes a negative shift to $98.1 \mathrm{eV}$, which can be assigned to $\mathrm{Li}-\mathrm{Si}$ alloy formed by the alloying reaction of $\mathrm{Si}$ with $\mathrm{Li}^{+} \cdot{ }^{37}$ Moreover, for the Si 2p spectrum at the discharge state, besides the dominant component at $98.1 \mathrm{eV}$, two extra weak components at $99.5 \mathrm{eV}$ and $100.7 \mathrm{eV}$ are also observed, corresponding to $\mathrm{Li}_{x} \mathrm{Si}_{y} \mathrm{C}$ and $\mathrm{SiC}$ respectively. $\mathrm{Li}_{x} \mathrm{Si}_{y} \mathrm{C}$ is formed by the irreversible reaction of $\mathrm{SiC}$ with $\mathrm{Li}^{+}$as shown in the eqn (3). This irreversible reaction with the formation of $\mathrm{Li}_{x} \mathrm{Si}_{y} \mathrm{C}$ would consume $\mathrm{Li}^{+}$, thus resulting in the lower coulombic efficiency of the SiC anode than the Si one in the initial cycle as mentioned in Fig. 4 . The existence of $\mathrm{SiC}$ at the fully discharge state suggests that there is some residual $\mathrm{SiC}$ in the anode not participating in the reactions, thus contributing to the lower capacity of the SiC sample

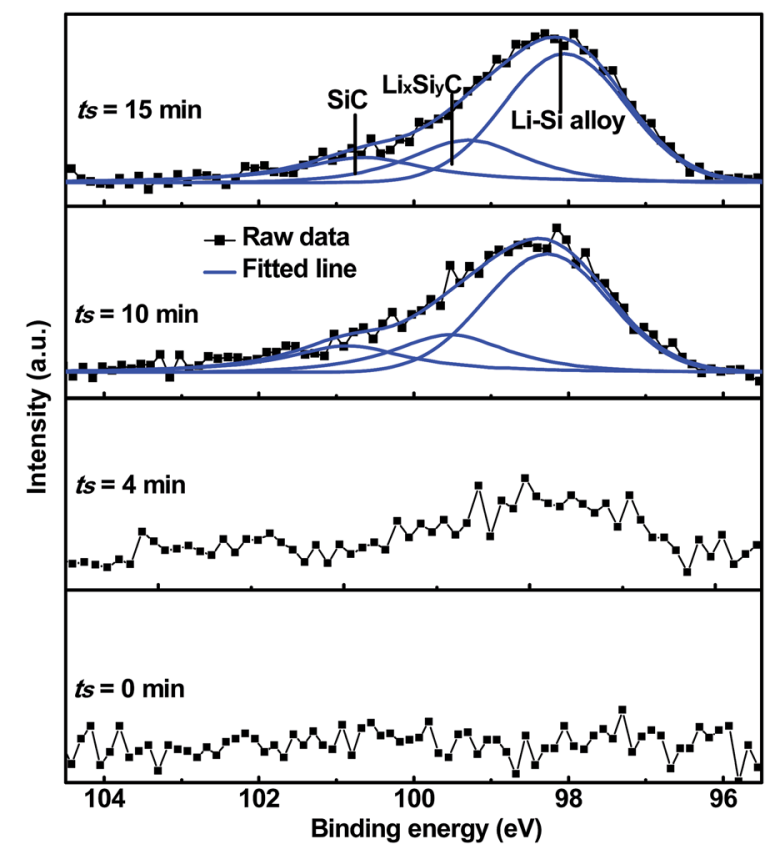

Fig. 5 Si $2 p$ XPS spectrum as a function of $\mathrm{Ar}^{+}$sputtering time for the $500 \mathrm{~nm} \mathrm{SiC}$ anode film at a fully discharge (0.01 V) state. than the Si one. According to Fig. 5, the relative atomic content of the $\mathrm{Si}-\mathrm{Li}$ alloy, $\mathrm{Li}_{x} \mathrm{Si}_{y} \mathrm{C}$ and $\mathrm{SiC}$ components in the anode (as $t_{\mathrm{s}}$ $\geq 10 \mathrm{~min}$ ) is about $61.2 \%, 20.5 \%$ and $18.3 \%$ respectively. It is noted that among each component in the anode, only the formation of Si-Li alloy contributes to the anode reversible capacity. Combining the SiC charge capacity in the initial cycle ( $\sim 1400 \mathrm{~mA} \mathrm{~h} \mathrm{~g}^{-1}$ from Fig. 4) with the relative content of the $\mathrm{Si}-\mathrm{Li}$ alloy component in the anode $(\sim 61.2 \%$ from Fig. 5$)$, the value of $y$ in the eqn (3) can be calculated to be 0.22 . Moreover, regarding the coulombic efficiency of the $\mathrm{SiC}$ anode in the initial cycle ( $\sim 86.0 \%$ from Fig. 4$)$, the value of $x$ and $y$ in the eqn (3) should meet the following expression

$$
\frac{x}{4.4(1-y)}<1-86.0 \%
$$

According to the above expression, the value of $x$ should be less than 0.48. Moreover, as discussed earlier, the irreversible reaction (3) induces a slope in the range of $0.5-1.5 \mathrm{~V}$ at the initial stage of the first discharge process (as seen in Fig. 4(a)) and the corresponding irreversible capacity of this slope is about $60 \mathrm{~mA} \mathrm{~h} \mathrm{~g}{ }^{-1}$ according to Fig. 4(a). Combining this irreversible capacity with the relative $\mathrm{Li}_{x} \mathrm{Si}_{y} \mathrm{C}$ content $(\sim 20.5 \%$ from Fig. 5) in the anode, the value of $x$ can be determined to be 0.44 . This extracted $x$ value satisfies the expression (5) well. It is noted that this irreversible capacity only accounts for a tiny portion of the whole capacity ( 1595 $\mathrm{mA} \mathrm{h} \mathrm{g}^{-1}$ as seen in Fig. 4(a)), leading to that the features corresponding to this irreversible reaction is not obvious in the CV and charge/discharge curves.

Fig. 6 shows the cycling characteristics of the $\mathrm{Si}$ and $\mathrm{SiC}$ samples at a $0.3 \mathrm{C}$ charge/discharge current, and both display a high CE $(>98.0 \%)$ after going through several cycles. For the $500 \mathrm{~nm} \mathrm{SiC} \mathrm{sample,} \mathrm{the} \mathrm{initial} \mathrm{discharge} \mathrm{reversible} \mathrm{capacity} \mathrm{is}$ $917 \mathrm{~mA} \mathrm{~h} \mathrm{~g}^{-1}$ and degrades gradually to $376 \mathrm{~mA} \mathrm{~h} \mathrm{~g}^{-1}$ after 100 cycles, corresponding to a capacity retention of $41.0 \%$. For comparison, the initial capacity of the $\mathrm{Si}$ sample is

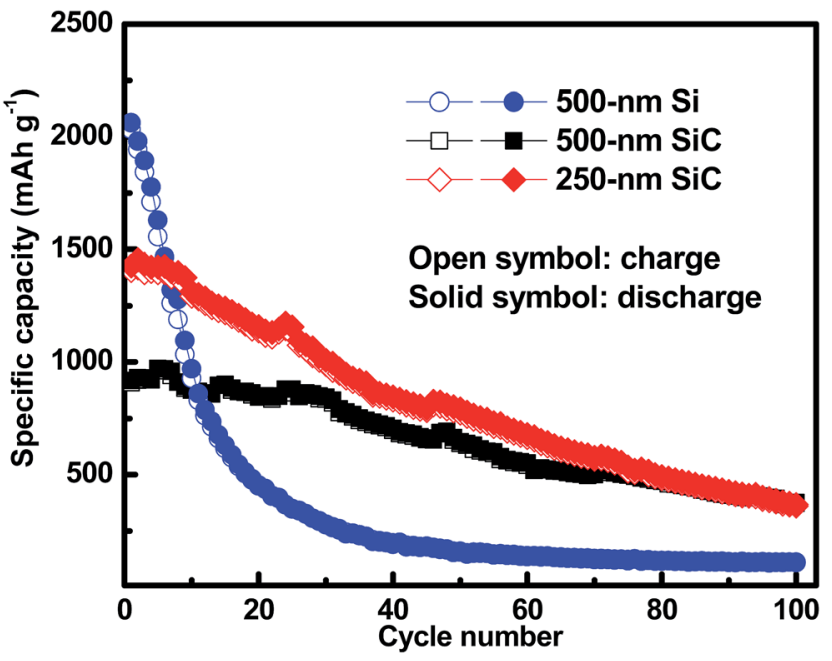

Fig. 6 Galvano-static cycling of the $\mathrm{Si}$, thin $\mathrm{SiC}$ and thick $\mathrm{SiC}$ samples at a current density of $0.3 \mathrm{C}$. The samples are activated at a low current density of $0.01 \mathrm{C}$ before test. 

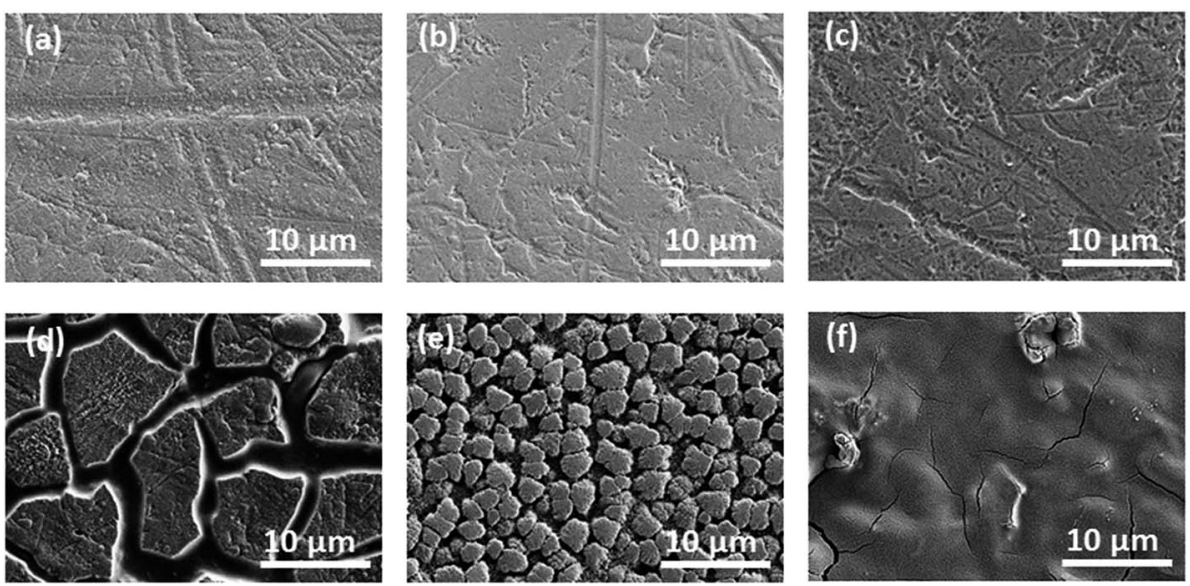

Fig. 7 SEM images of the samples before cycling: (a) $500 \mathrm{~nm} \mathrm{Si}$, (b) $250 \mathrm{~nm} \mathrm{SiC}$ and (c) $500 \mathrm{~nm} \mathrm{SiC}$; SEM images of the samples after cycling: (d) $500 \mathrm{~nm} \mathrm{Si},(e) 250 \mathrm{~nm} \mathrm{SiC}$ and (f) $500 \mathrm{~nm} \mathrm{SiC}$

$2062 \mathrm{~mA} \mathrm{~h} \mathrm{~g}^{-1}$, and its capacity decreases drastically at first and then remains constant with cycling, corresponding to a capacity retention of $5.2 \%$ after 100 cycles. It is obvious that the SiC sample exhibits much better capacity retention than the Si one. The SiC sample displays lower specific capacity in the initial cycles than the Si one partially due to its incomplete reaction as demonstrated in Fig. 5. For practical applications, relatively thick SiC and Si films ( $\sim 500 \mathrm{~nm})$ are utilized for improving the anode capacity in this work. However, the thick anode film would reduce the anode conductivity (and thus the reaction kinetics). This has more severe influence on the $\mathrm{SiC}$ anode than the $\mathrm{Si}$ one mainly because of its lower activity than the latter, ${ }^{25,29,30}$ thus resulting in residual $\mathrm{SiC}$ component in the $\mathrm{SiC}$ sample even after repeated cycling (as seen in Fig. 5). As demonstrated in Fig. 6, decreasing the SiC thickness is effective to enhance the reaction kinetics and thus increase the specific capacity (the initial capacity is $1427 \mathrm{~mA} \mathrm{~h} \mathrm{~g}^{-1}$ and $917 \mathrm{~mA} \mathrm{~h} \mathrm{~g}^{-1}$ for the $250 \mathrm{~nm}$ and $500 \mathrm{~nm}$ SiC respectively). ${ }^{21,23}$ The capacity retention for the thin $\mathrm{SiC}$ anode is $25.7 \%$ after 100 cycles. One interesting phenomenon is that the thin SiC anode $(\sim 25.7 \%)$ displays worse capacity retention than the thick one $(\sim 41.0 \%)$. It is known that a thinner anode film has stronger ability to suppress the stress induced material degradation caused by repeated cycling; consequently, the thin anode film usually exhibits better capacity retention than the thick one. ${ }^{6,21,23}$ However, in this work, the better capacity retention for the thick SiC sample than the thin one suggests that the residual SiC component (caused by the incomplete reaction) in the anode film plays a critical role in improving the capacity retention. The $\mathrm{SiC}$ has very high hardness ( $c a .18 \mathrm{GPa} v s .11 \mathrm{GPa}$ for $\mathrm{Si}$ ), ${ }^{43,44}$ which can act as a buffer matrix surrounding the active anode materials, thus suppressing the volume change as well as its induced stress during repeated cycling. It is noted that the film hardness would decrease rapidly after $\mathrm{Li}^{+}$insertion into the film; ;5,46 therefore, it is believed that the $\mathrm{Li}_{x} \mathrm{Si}_{y} \mathrm{C}$ component formed by the irreversible reaction shown in (3) has less contribution to the capacity retention than the SiC component due to its lower hardness. Fig. 7 exhibits the SEM images of the
$\mathrm{Si}$, thin SiC and thick SiC samples before and after cycling. The $\mathrm{Si}$ and thin $\mathrm{SiC}$ anodes after cycling break into pieces mainly because of its severe volume change induced by the repeated cycling, thus leading to their low capacity retention. On the contrary, the thick SiC film after cycling is almost intact with only a few hairline cracks, demonstrating that the thick SiC film has much better mechanical stability, thus resulting in its better capacity retention.

\section{Conclusion}

$500 \mathrm{~nm}$ SiC film prepared by ICP-CVD is investigated as the LIB anode by comparison with the Si film. The SiC film is amorphous due to the low processing temperature, which is beneficial for the anode performance. An irreversible reaction of SiC with $\mathrm{Li}^{+}$occurs with a formation of $\mathrm{Li}_{x} \mathrm{Si}_{y} \mathrm{C}$ and $\mathrm{Si}$, followed by a reversible alloying/dealloying reaction of the $\mathrm{Si}$ with $\mathrm{Li}^{+}$. This irreversible reaction of the $\mathrm{SiC}$ anode is responsible for its lower coulombic efficiency than the Si anode in the initial cycles. In addition, due to the low activity of the SiC anode, residual SiC component exists in the SiC anode even after repeated electrochemical cycling. This residual SiC reduces the specific capacity of the anode. On the other hand, this residual SiC can act as a buffer matrix surrounding the active materials to alleviate the volume change, thus improving the mechanical stability and capacity retention of the $\mathrm{SiC}$ anode compared with the Si one.

\section{Conflicts of interest}

There are no conflicts to declare.

\section{Acknowledgements}

This work was supported in part by the Natural Science Foundation of Jiangsu Province under Grant BK20140639 and in part by the National Natural Science Foundation of China under Grant 21206076. 


\section{References}

1 Y. Wang, B. Liu, Q. Li, S. Cartmell, S. Ferrara, Z. D. Deng and J. Xiao, Lithium and Lithium Ion Batteries for Applications in Microelectronic Devices: A Review, J. Power Sources, 2015, 286, 330.

2 B. Fleutot, B. Pecquenard, F. Le Cras, B. Delis, H. Martinez, L. Dupont and D. Guy-Bouyssou, Characterization of AllSolid-State Li/LiPONB/TiOS Microbatteries Produced at the Pilot Scale, J. Power Sources, 2011, 196, 10289.

3 W. Lai, C. K. Erdonmez, T. F. Marinis, C. K. Bjune, N. J. Dudney, F. Xu, R. Wartena and Y. Chiang, UltrahighEnergy-Density Microbatteries Enabled by New Electrode Architecture and Micropackaging Design, Adv. Mater., 2010, 22, 139.

4 L. Baggetto, R. A. H. Niessen, F. Roozeboom and P. H. L. Notten, High Energy Density All-Solid-State Batteries: A Challenging Concept Towards 3D Integration, Adv. Funct. Mater., 2008, 18, 1057.

5 R. Janski, M. Fugger, M. Sternad and M. Wilkening, Lithium Distribution in Monocrystalline Silicon-Based Lithium-Ion Batteries, ECS Trans., 2014, 62, 247.

6 U. Kasavajjula, C. Wang and A. F. Appleby, Nano-and BulkSilicon-Based Insertion Anodes for Lithium-Ion Secondary Cells, J. Power Sources, 2007, 163, 1003.

7 H. Wu, G. Chan, J. W. Choi, I. Ryu, Y. Yao, M. T. McDowell, S. W. Lee, A. Jackson, Y. Yang, L. Hu and Y. Cui, Stable Cycling of Double-Walled Silicon Nanotube Battery Anodes Through Solid-Electrolyte Interphase Control, Nat. Nanotechnol., 2012, 7, 310.

8 B. Liu, P. Soares, C. Checkles, Y. Zhao and G. Yu, ThreeDimensional Hierarchical Ternary Nanostructures for High Performance Li-Ion Battery Anodes, Nano Lett., 2013, 13, 3414.

9 E. Luais, F. Ghanmouss, J. Wolfman, S. Desplobain, G. Gautier, F. Tran-Van and J. Sakai, Mesoporous Silicon Negative Electrode for Thin Film Lithium-Ion Microbatteries, J. Power Sources, 2015, 274, 693.

10 M. Green, E. Fielder, B. Scrosati, M. Wachtler and J. S. Moreno, Structured Silicon Anodes for Lithium Battery Applications, Electrochem. Solid-State Lett., 2003, 6, A75.

11 C. Yu, X. Li, T. Ma, J. Rong, R. Zhang, J. Shaffer, Y. An, Q. Liu, B. Wei and H. Jiang, Silicon Thin Films as Anodes for HighPerformance Lithium-Ion Batteries with Effective Stress Relaxation, Adv. Energy Mater., 2012, 2, 68.

12 J. Ryu, D. Hong, S. Choi and S. Park, Synthesis of Ultrathin Si Nanosheets from Natural Clays for Lithium-Ion Battery Anodes, ACS Nano, 2016, 10, 2843.

13 X. H. Wang, L. M. Sun, R. A. Susantyoko, Y. Fan and Q. Zhang, Ultrahigh Volumetric Capacity Lithium Ion Battery Anodes with CNT-Si Film, Nano Energy, 2014, 8, 71.

14 Z. Favors, W. Wang, H. H. Bay, A. George, M. Ozkan and C. Ozkan, Stable Cycling of $\mathrm{SiO}_{2}$ Nanotubes as HighPerformance Anodes for Lithium-Ion Batteries, Sci. Rep., 2014, 4, 4605.
15 M. Miyachi, H. Yamamoto, H. Kawai, T. Ohta and M. Shirakata, Analysis of SiO Anodes for Lithium-Ion Batteries, J. Electrochem. Soc., 2005, 152, A2089.

16 Y. Yao, J. J. Zhang, L. G. Xue, T. Huang and A. Yu, CarbonCoated $\mathrm{SiO}_{2}$ Nanoparticles as Anode material for Lithium Ion Batteries, J. Power Sources, 2011, 196, 10240.

17 N. Yan, F. Wang, H. Zhong, Y. Li, Y. Wang, L. Hu and Q. Chen, Hollow Porous $\mathrm{SiO}_{2}$ Nanocubes Towards HighPerformance Anodes for Lithium-Ion Batteries, Sci. Rep., 2013, 3, 1568.

18 Y. F. Zhang, Y. J. Li, Z. Y. Wang and K. Zhao, Lithiation of $\mathrm{SiO}_{2}$ in Li-Ion Batteries: In Situ Transmission Electron Microscopy Experiments and Theoretical Studies, Nano Lett., 2014, 14, 7161.

19 M. Gil, M. E. Rabanal, A. Varez, A. Kuhn and F. GarciaAlvarado, Mechanical Grinding of $\mathrm{Si}_{3} \mathrm{~N}_{4}$ to Be Used as an Electrode in Lithium Batteries, Mater. Lett., 2003, 57, 3063.

20 D. Ahn, C. Kim, J. Lee and B. Park, The Effect of Nitrogen on the Cycling Performance in Thin-Film $\mathrm{Si}_{1-x} \mathrm{~N}_{x}$ Anode, J. Solid State Chem., 2008, 181, 2139.

21 J. Yang, R. C. Guzman, S. O. Salley, K. Y. Simon, B. Chen and M. M. Cheng, Plasma Enhanced Chemical Vapor Deposition Silicon Nitride for a High-Performance Lithium Ion Battery Anode, J. Power Sources, 2014, 269, 520.

22 C. Y. Wu, C. C. Chang and J. G. Duh, Silicon Nitride Coated Silicon Thin Film on Three Dimensions Current Collector for Lithium Ion Battery Anode, J. Power Sources, 2016, 325, 64.

23 N. Suzuki, R. B. Cervera, T. Ohnishi and K. Takada, Silicon Nitride Thin Film Electrode for Lithium-Ion Batteries, $J$. Power Sources, 2013, 231, 186.

24 R. Yi, F. Dai, M. L. Gordin, S. Chen and D. Wang, Micro-Sized Si-C Composite with Interconnected Nanoscale Building Blocks as High-Performance Anodes for Practical Application in Lithium-Ion Batteries, Adv. Energy Mater., 2013, 3, 295.

25 X. H. Chang, W. Li, J. F. Yang, L. Xu, J. Zheng and X. G. Li, Direct Plasma Deposition of Amorphous $\mathrm{Si} / \mathrm{C}$ Nanocomposites as High Performance Anodes for Lithium Ion Batteries, J. Mater. Chem. A, 2015, 3, 3522.

26 Y. Yang, J. G. Ren, X. Wang, Y. S. Chui, Q. H. Wu, X. F. Chen and W. J. Zhang, Graphene Encapsulated and SiC Reinforced Silicon Nanowires as an Anode Material for Lithium Ion Batteries, Nanoscale, 2013, 5, 8689.

27 I. H. Son, J. H. Park, S. Kwon, S. Park, M. H. Rummeli, A. Bachmatiuk, H. J. Song, J. Ku, J. W. Choi, J. Choi, S. Doo and H. Chang, Silicon Carbide-Free Graphene Growth on Silicon for Lithium-Ion Battery with High Volumetric Energy Density, Nat. Commun., 2015, 6, 7379.

28 M. Yoshi, H. Wang, K. Fukuda, T. Umeno, N. Dimov and Z. Ogumi, Carbon-Coated $\mathrm{Si}$ as a Lithium-Ion Battery Anode Material, J. Electrochem. Soc., 2002, 149, A1598.

29 I. S. Kim, G. E. Blomgren and P. N. Kumta, Si-SiC Nanocomposites Anodes Synthesized Using High-Energy Mechanical Milling, J. Power Sources, 2004, 130, 275. 
30 B. J. Jeon and J. K. Lee, Electrochemical Characteristics of nc$\mathrm{Si} / \mathrm{SiC}$ Composite for Anode Electrode of Lithium Ion Batteries, J. Alloys Compd., 2014, 590, 254.

31 Y. Sakai and A. Oshiyama, Electron Doping Through Lithium Intercalation to Interstitial Channels in Tetrahedrally Bonded SiC, J. Appl. Phys., 2015, 118, 175704.

32 H. T. Zhang and H. Xu, Nano Crystalline Silicon Carbide Thin Film Electrodes for Lithium-Ion Batteries, Solid State Ionics, 2014, 263, 23.

33 T. S. Kumari, D. Jeyakumar and T. P. Kumar, Nano Silicon Carbide: A New Lithium-Insertion Anode Material on the Horizon, RSC Adv., 2013, 3, 15028.

34 Y. W. Hu, X. S. Liu, X. P. Zhang, N. Wan, D. Pan, X. J. Li and Y. Bai, Bread-Curtain Shaped SiC@SiO ${ }_{2}$ Core-Shell Nanowires with Superior Electrochemical properties for Lithium-Ion Batteries, Electrochim. Acta, 2016, 190, 33.

35 M. Shiratani, K. Kamataki, G. Uchida, K. Koga, H. Seo, N. Itagaki and T. Ishihara, SiC Nanoparticle Composite Anode for Li-Ion Batteries, Mater. Res. Soc. Symp. Proc., 2014, 1678.

36 https:/www.oxford-instruments.com/products/etchingdeposition-and-growth/processes/deposition-processes/ others/sic-deposition/sic-icp-cvd.

37 C. K. Chan, R. Ruffo, S. S. Hong and Y. Cui, Surface Chemistry and Morphology of the Solid Electrolyte Interphase on Silicon Nanowire Lithium-Ion Battery Anodes, J. Power Sources, 2009, 189, 1132.

38 Y. Xia, R. Fang, Z. Xiao, L. Ruan, R. Yan, H. Huang, C. Liang, Y. Gan, J. Zhang, X. Tao and W. Zhang, Supercritical Fluid Assisted Biotemplating Synthesis of Si-O-C Microspheres
From Microalgae for Advanced Li-Ion Batteries, RSC Adv., 2016, 6, 69674.

39 E. Uchaker, Y. Z. Zheng, S. Li, S. L. Candelaria, S. Hu and G. Z. Cao, Better Than Crystalline: Amorphous Vanadium Oxide for Sodium-Ion Batteries, J. Mater. Chem. A, 2014, 2, 18208.

40 Y. Jiang, D. Zhang, Y. Li, T. Yuan, N. Bahlawane, C. Liang, W. Sun, Y. $\mathrm{Lu}$ and M. Yan, Amorphous $\mathrm{Fe}_{2} \mathrm{O}_{3}$ as a HighCapacity, High-Rate and Long-Life Anode Material for Lithium Ion Batteries, Nano Energy, 2014, 4, 23.

41 M. T. McDowell, S. W. Lee, J. T. Harris, B. A. Korgel, C. Wang, W. D. Nix and Y. Cui, In situ TEM of Two-Phase Lithiation of Amorphous Silicon Nanospheres, Nano Lett., 2013, 13, 758.

42 F. Wang, R. Robert, N. A. Chernova, N. Pereira, F. Omenya, F. Badway, X. Hua, M. Ruotolo, R. Zhang, L. Wu, V. Volkov, D. Su, B. Key, M. S. Whittingham, C. P. Grey, G. G. Amatucci, Y. Zhu and J. Graetz, Conversion Reaction Mechanisms in Lithium Ion Batteries: Study of the Binary Metal Fluoride Electrodes, J. Am. Chem. Soc., 2011, 133, 18828.

43 https://www.memsnet.org/material/siliconcarbidesicfilm/. 44 https://www.memsnet.org/material/siliconsibulk/.

45 B. Hertzberg, J. Benson and G. Yushin, Ex Situ DepthSensing Indentation Measurements of Electrochemically Produced Si-Li Alloy Films, Electrochem. Commun., 2011, 13, 818.

46 X. Wang, S. S. Singh, T. Ma, C. Lv, N. Chawla and H. Jiang, Quantifying Electrochemical Reactions and Properties of Amorphous Silicon in a Conventional Lithium-Ion Battery Configuration, Chem. Mater., 2017, 29, 5831. 